\title{
Removal of heavy metals using kaolinite and Bentonite filter media
}

\author{
Ghada Heikal* \\ Environmental Engineering Department, Faculty of Engineering, Zagazig University, Postal code 44519, Egypt
}

Received 04 Sept 2018, Accepted 06 Nov2018, Available online 08 Nov, Vol.8, No.6 (Nov/Dec 2018)

\begin{abstract}
Heavy metals are among the most lethal pollutants of surface water. The main sources of heavy metals are industrial wastes from processes such as mining operations and ore processing, smelter, textile, leather dyeing, coating, metal finishing, chemical manufacturing, refineries, power generation and nuclear fuel processing. The concentration of heavy metals should be reduced to the acceptable levels before discharged into the environment because these are non degradable into nontoxic metals end products and the well known damaging effects of heavy metals on human being and other habitants. Sets of experiments were carried out to examine the ability of (kaolinite and bentonite) to reduce the concentration of chromium and cadmium ions in raw synthetic wastewater using upflow filter respectively. The main parameters were solution $\mathrm{pH} 2-6$, retention time 12-72 hrs, the initial concentration of pollutants 100-500 ppm and filter media height 10.5-42 cm. All data were analyzed by regression analysis model to correlate the different boundary conditions. The highest achieved \% removal efficiency of Cr and Cd were $96 \%$ and $91 \%$ through kaolinite and bentonite clay filter media at pH 6.0 and 5.0 respectively, retention time 24 hr, initial concentration $100 \mathrm{ppm}$ and filter media height $42 \mathrm{~cm}$. The results of regression models indicate that the most influential independent variables in the \% removal efficiency of $\mathrm{Cr}$ and $\mathrm{Cd}$ ions from aqueous solutions using kaolinite and bentonite clay upflow filter $\mathrm{pH}$, retention time and height media filter, which affects positively. Results of the experimental data show that the best empirical correlation achieved the highest fitting of predicted \% removal of Cr and Cd using kaolinite and bentonite clay separately that gives the highest value of $\left(R^{2}=0.995\right.$ and 0.988$)$ respectively.
\end{abstract}

Keywords:Filtration, Clay, Heavy metals, synthetic wastewater

\section{Introduction}

The world's supply of spotless and safe waters for human utilization and requirements is ending up increasingly rare because of different anthropogenic and industrial activities. Such exercises have definitely discharged significant measures of wastewater containing lethal substances, in this manner representing extraordinary natural worries for a long time. Substantial metals are comprehensively characterized as those metals and metalloids of moderately high particular gravity (no less than five times that of water) or of high relative nuclear weight, which are thought to be of adequate dispersal and predominance as to be somehow earth or organically huge as harmful components. Heavy metal sullying happens in fluid misuse of numerous ventures which is at last arranged to arrive or in water courses. Since a large portion of the heavy metals are non-degradable into non-poisonous final results, their fixations must be diminished to adequate levels previously releasing them into the environment (Kurniawanet al., 2014).

*Corresponding author's ORCID ID: 0000-0002-9552-6894 DOI: https://doi.org/10.14741/ijcet/v.8.6.3
Heavy metals harming of people by means of inward breath, ingestion and skin assimilation can bring about lessened mental and focal apprehensive functions, changes in various metabolic body procedures and harm to blood piece, kidneys, lungs, liver and other crucial organs. Long haul introduction may bring about degeneration of physical, solid and neurological capacities that imitates Parkinson's sickness, Alzheimer's infections, strong dystrophy and various scleroses. Overwhelming metals rich effluents are released from numerous businesses around the world, for example, electroplating, mining, metal completing, photographic, ammo, cowhide tanning, material and coloring, composts, batteries, combinations and electronic merchandise producing as well as from rural exercises to a lesser degree (Amarasinghe and Williams, 2007).

This paper concentrates its experimentation on using upflow filter media made up of kaolinite and Bentonite clay to treat raw synthetic wastewater contains heavy metal ions solution of $\mathrm{Cr}$ and $\mathrm{Cd}$ effluent which simulates textile industrial wastewater. The objective of this study is to develop a method for the removal of total chromium and cadmium ions in 
synthetic wastewater solutions. Since earlier studies have shown potential for removal of $\mathrm{Cr}$ and $\mathrm{Cd}$ with natural clays, the aim will be reached by answering the following questions:

- Can two different clays represented as kaolinite and bentonite be used separately as filter media potential effectiveness for $\mathrm{Cr}$ and $\mathrm{Cd}$ removal?

- Is it possible to optimize the removal efficiency of chromium and cadmium by adjusting $\mathrm{pH}$, operating treatment time, initial concentration of heavy metals ions solution andmedia filter height?

\section{Materials and Method}

\subsection{Study Area and Preparation of Synthetic Wastewater}

This study has been conducted in Environmental Engineering Laboratory, Faculty of Engineering, Zagazig University by preparing the heavy metal ions solutions from (Potassium dichromateand Cadmium chloride) were prepared of analytical reagent grade stock standard of concentration $1000 \mathrm{ppm}$. The $\mathrm{pH}$ of the wastewater was adjusted by using $0.1 \mathrm{M} \mathrm{HCl}$ and/or $\mathrm{NaOH}$. The final concentration of heavy metal ions in the synthetic wastewater was analyzed by atomic absorption spectrophotometer type(AAS) (model 200 AA 240 Varian).

\subsection{Study Design}

Continuous mode comparative experimental study design has been carried out to determine the efficiency of kaolinite and bentoniteupflow filter media on the treatment of synthetic wastewater contains heavy metal ions solution of $\mathrm{Cr}$ and $\mathrm{Cd}$ effluent, in the case of simulating textile wastewater filtration.

\subsection{Experimental materials, Design and setup Establishments}

The kaolinite and bentonite clays were bought from Industrial Zone - ELBasatin, Cairo, Egypt. The chemical compositions of the used clays were determined in (Table 1).

\begin{tabular}{|c|c|c|}
\hline Chemical Composition & $\begin{array}{c}\text { Percent Weight } \\
\text { of kaolinite }\end{array}$ & $\begin{array}{c}\text { Percent Weight of } \\
\text { bentonite }\end{array}$ \\
\hline $\mathrm{SiO2}$ & $43.94 \%$ & $55.22 \%$ \\
\hline $\mathrm{Al2O} 3$ & $37.4 \%$ & $21.00 \%$ \\
\hline $\mathrm{Fe} 203$ & $1.19 \%$ & $0.92 \%$ \\
\hline $\mathrm{CaO}$ & $0.06 \%$ & $4.94 \%$ \\
\hline $\mathrm{K} 20$ & $0.02 \%$ & $1.56 \%$ \\
\hline $\mathrm{Na20}$ & $0.10 \%$ & $3.03 \%$ \\
\hline Mg0 & $0.11 \%$ & 0.96 \\
\hline TiO2 & $2.84 \%$ & $10.28 \%$ \\
\hline H20 & $0.54 \%$ & 9.5 \\
\hline \multicolumn{2}{|c|}{ physical properties, Particle size $=0.075-0.425 \mathrm{~mm}}$. \\
\hline Porosity (\%) & 4.8 & 2.07 \\
\hline Particle density (gcm-3) & $2.5-2.65$ & 27.6 \\
\hline $\begin{array}{c}\text { Specific surface area } \\
\text { (BET) (m2 g-1) }\end{array}$ & 31.2 & $90-111$ \\
\hline $\begin{array}{c}\text { Cation exchange capacity } \\
\text { (CEC), mequiv. 100 g-1 }\end{array}$ & $2-10$ & \\
\hline
\end{tabular}

In this study, a simple Perspex cylindrical filter was manufactured with the following dimensions: Length = $50 \mathrm{~cm}$, Internal diameter $=8 \mathrm{~cm}$ and Outer diameter $=$ $10 \mathrm{~cm}$. Base is covered with a porous plate of $5 \mathrm{~mm}$ diameter pores. The cylindrical filter column provided with 4 openings at distances $10.5 \mathrm{~cm}$ between each other measured from the base of filter column to study the effect of clay media height. In order to test the influence of different types of clays (kaolinite and bentonite) on the removal efficiency of chromium and cadmium from raw synthetic wastewater contains heavy metal ions, two different packing orders of filter media were applied to the manufactured filter. Fig (1) showed a schematic layout for the components of the upflow filter column all dimensions in (cm).

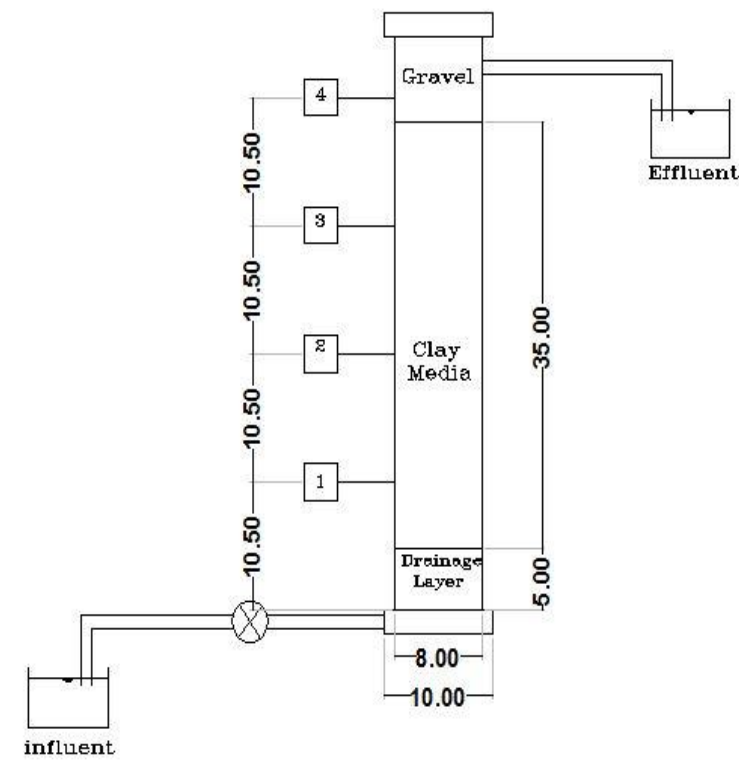

Fig 1Schematic layout for the components of the upflow filter column

The experiments operated as continuous upflow system. These filter mediums were crushed and graded. Effective size was determined by using standard sieve. Based on the analysis the effective size (ES) (d10) of each media was $1.5-4.5$ and the uniformity coefficient (UC) (d60/d10) is $3.5-4$. After grading the filter materials were washed by tap water and dray by sunlight for Five days. After installation the filter media was filled in the filtration tank $5 \mathrm{~cm}$ depth with 10 - $15 \mathrm{~mm}$ grain size drainage layer at the bottom, $35 \mathrm{~cm}$ depth clay filter layer with a grain size of $1.5-4.5 \mathrm{~mm}$ at the middle and distribution layer $\left(1^{\mathrm{st}}\right.$ run with kaolinite clay and $2^{\text {nd }}$ run with bentonite clay), (flat coarse gravel) was added $5 \mathrm{~cm}$ depth at the top of the filter media to protect erosion of filter's top layer. For each run, the operating conditions were $\mathrm{pH}$ ranged from 2 to 6 , retention time ranged from $12 \mathrm{hr}$ to $72 \mathrm{hr}$, initial concentration ranged from $100 \mathrm{ppm}$ to $500 \mathrm{ppm}$ and height of media filter was 10.5, 21, 31.5 and $42 \mathrm{~cm}$. Theraw synthetic wastewater contains heavy metal ions discharged through the filter media of 
the pump ranged $(0.015-0.3)$ lit/min. The pump was Digital Watson Marlow model 505S.

\subsection{Laboratory Analysis and Measurements:}

The physicochemical analysis of wastewater samples has been done using standard methods. First, optimum operating $\mathrm{pH}$ was determined for maximum removal of $\mathrm{Cr}$ and $\mathrm{Cd}$ ions by running the experiment for $2,3,4,5$ and 6. Further experiment at solution $\mathrm{pH}$ above 6.0 was not conducted because of the precipitation of the chromium and cadmium occurring in the solution (Bassett et al., 1978). Second, at the optimum $\mathrm{pH}$, optimum retention time was determined for maximum removal of $\mathrm{Cr}$ and $\mathrm{Cd}$ ions by running the experiment for 12, 24, 48 and 72 hours, respectively. Third, at the optimum $\mathrm{pH}$ and operating treatment time, the optimum initial concentrations of $\mathrm{Cr}$ and $\mathrm{Cd}$ ions were determined for maximum removal of $\mathrm{Cr}$ and $\mathrm{Cd}$ ions by running the experiment for 100, 200, 300, 400 and 500 ppm, respectively. Finally, at the optimum $\mathrm{pH}$, operating treatment time and the initial concentrations, optimum height of media filter was determined for maximum removal of $\mathrm{Cr}$ and $\mathrm{Cd}$ ions by running the experiment for 10.5, 21, 31.5 and $42 \mathrm{~cm}$, respectively. Filtrated Sample was taken by 1 liter plastic bottle after each fixed retention time that is after 12, 24, 48 and 72 hours and the analytical parameters were Cadmium and chromium. $\mathrm{pH}$ were measured by AD1000 (pH/mv)\& temperature meter. Determination of $\mathrm{Cr}$ and $\mathrm{Cd}$ concentrations in raw synthetic wastewater contains heavy metal ions samples were done according to APHA (2005) using Atomic Absorption Sperctrophotometer (AAS) (model 200 AA 240 Varian) at wave length 357.9 and 326.1 respectively. A standard line was prepared by plotting the absorbance reading on $\mathrm{Y}$-axis versus the concentration of each standard solution of $\mathrm{Cr}$ and $\mathrm{Cd}$ on X-axis. The concentrations of $\mathrm{Cr}$ and $\mathrm{Cd}$ were calculated by plotting AAS reading on the standard line as shown in fig. (2) \& (3) respectively.

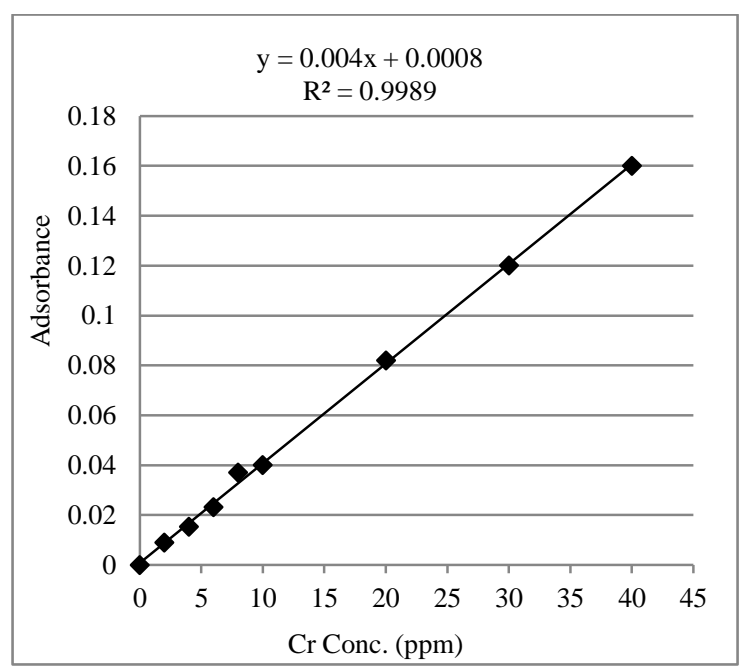

Fig.2 Calibration curve of chromium

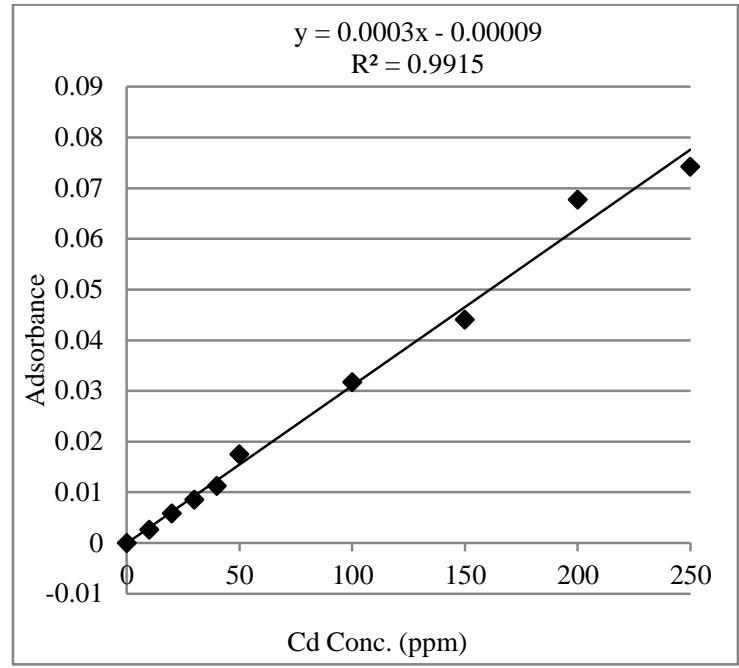

Fig.3 Calibration curve of cadmium

The removal efficiency of the filter media for the selected parameters was calculated as:

$\%$ removal $=\left[\mathrm{C}_{\mathrm{i}}-\mathrm{C}_{\mathrm{f}}\right] / \mathrm{C}_{\mathrm{i}} \mathrm{X} 100$

Where $C_{i}$ is the parameter concentration in the untreated wastewater and $\mathrm{C}_{\mathrm{f}}$ is the parameter concentration in the treated wastewater.

\subsection{Data Quality Management}

To declare quality of the data by minimizing the errors the following measures had been undertaken: Apparatuses were calibrated; expiry date of reagents had been checked before starting the real analysis and standard control also prepared. Each test had triplicated.

\subsection{Statistical Analysis}

All experimental data of this study used to correlate the relationship between dependent and independent variables affecting on the removal efficiency of $\mathrm{Cr}$ and Cd ions using kaolinite and bentonite clays through regression analysis carried out with the help of Excel Software 2016. Regression analysis is a set of statistical processes for estimating the interaction among different variables. Regression analysis helps to understand how the typical value of the dependent variable changes when any one of the independent variables is varied, while the other independent variables are held fixed. In this study, there is one dependent variable (\% removal of $\mathrm{Cr}$ and $\mathrm{Cd}$ ions) based on four independent variables $(\mathrm{pH}$, retention time, initial concentration and media filter height). The regression analysis equation based on equation (1) to fit the experimental results. 
Where $\mathrm{Y}$ is the predicted results of $\mathrm{Cr}$ and $\mathrm{Cd}$ removal efficiency which is the dependent variable; $\mathrm{X}_{1}$ is $\mathrm{pH}(2-$ 6); $X_{2}$ is retention time(12, 24, 48 and $\left.72 \mathrm{hr}\right) ; X_{3}$ is initial concentration of $\mathrm{Cr}$ and $\mathrm{Cd}$ ions $(100,200,300$, 400 and $500 \mathrm{ppm}) ; \mathrm{X}_{4}$ is media filter height $(10.5,21$, 31.5 and $42 \mathrm{~cm}$ ); $\mathrm{a}, \mathrm{b}, \mathrm{c}$ and $\mathrm{d}$ are the linear coefficients of $\left(\mathrm{X}_{1}, \mathrm{X}_{2}, \mathrm{X}_{3}\right.$ and $\left.\mathrm{X}_{4}\right)$ which are the independent variables, respectively.

\section{Results and Discussion}

\subsection{Analysis of Acidity and Alkalinity}

The effect of acidity and alkalinity of chromium and cadmium solutions ions represented as $\mathrm{pH}$ value on the $\%$ removal of chromium and cadmium ions $(\mathrm{Cr}$ and $\mathrm{Cd}$ ions) is presented in Figure (4). The $\mathrm{pH}$ of the heavy metal solutions is an important operational parameter in the upflow filtration process. This is because it affects the solubility of the metal ions concentration of the counter ions on the functional groups of the clay filter media represented in individual kaolinite and bentonite clay and the degree of ionization of the $\mathrm{Cr}$ and $\mathrm{Cd}$ ions during reaction (Oladoja and Imohimi, 2005).

The effect of initial $\mathrm{pH}$ on $\mathrm{Cr}$ and $\mathrm{Cd}$ removal efficiency by the kaolinite and bentonite media filters separately are studied at $100 \mathrm{mg} / \mathrm{l} \mathrm{Cr}$ and $\mathrm{Cd}$ initial concentration as separate solutions with the retention time of $12 \mathrm{hr}$, media filter height $=42 \mathrm{~cm}$ and $\mathrm{pH}$ varied from 2.0 to 6.0. Fig. (4) shows that the \% removal efficiency of $\mathrm{Cr}$ increased with the increase of $\mathrm{pH}$ for both media filters. On the other hand, the \% removal efficiency of $\mathrm{Cd}$ increased with the increase of $\mathrm{pH}$ till it reached to 5.0 and then started to decrease for both media filters. The optimized $\mathrm{pH}$ for $\mathrm{Cr}$ and $\mathrm{Cd}$ removal efficiency by kaolinite and bentonite media filters separately were found to be 6.0 with $78 \%$ removal efficiency by kaolinite media filter and 5.0 with $71 \%$ removal efficiency by bentonite media filter respectively.

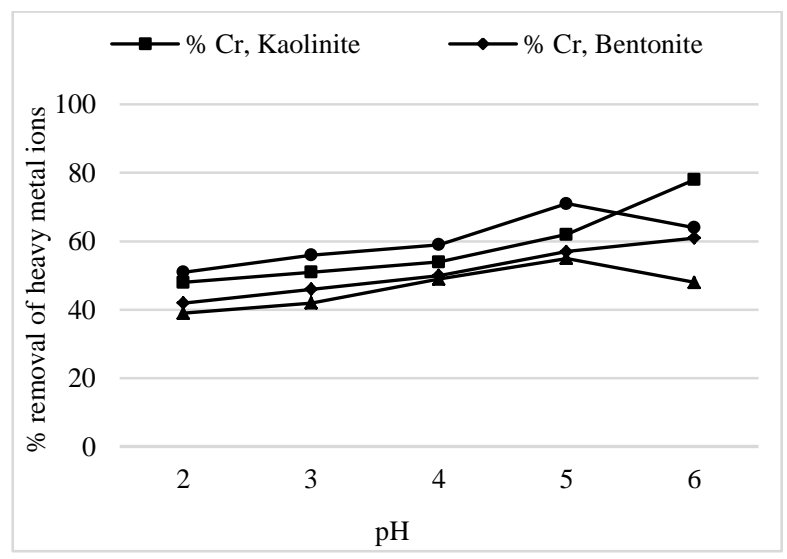

Fig.4\% removal of $\mathrm{Cr}$ and $\mathrm{Cd}$ based on $\mathrm{pH}$ using kaolinite and bentonite media filters at initial conc. $=100 \mathrm{ppm}$, the retention time of $12 \mathrm{hr}$ and media filter height $=42 \mathrm{~cm}$

\subsection{Analysis of Retention Time}

The effect of retention time on the removal efficiency of $\mathrm{Cr}$ and $\mathrm{Cd}$ from its solutions is shown in Fig.(5). The variation of percentage removal of $\mathrm{Cr}$ and $\mathrm{Cd}$ with retention time were studied using separately initial concentration of $\mathrm{Cr}$ and $\mathrm{Cd}=100 \mathrm{mg} / \mathrm{l}$ at optimized $\mathrm{pH}$ $=6.0$ and 5.0 respectively and media filter height $=42$ $\mathrm{cm}$. The retention time was varied from $12-72 \mathrm{hr}$.

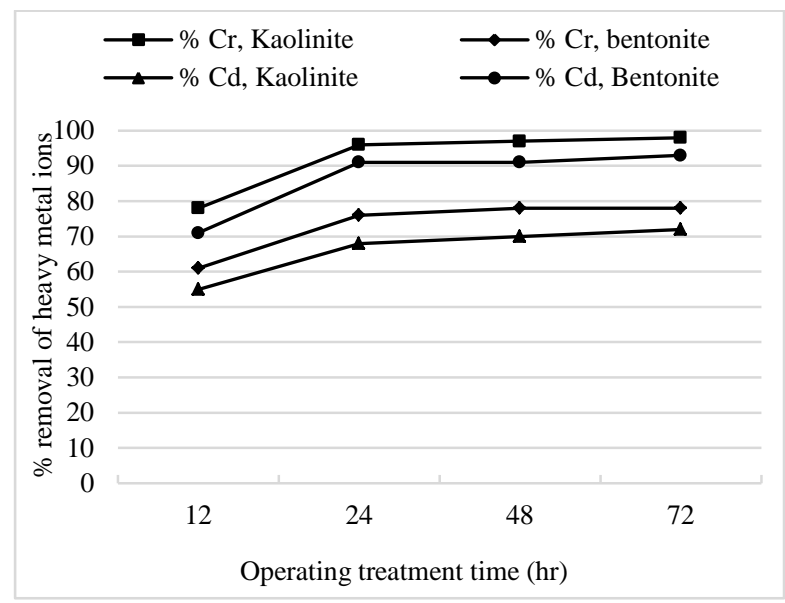

Fig.5\% removal of $\mathrm{Cr}$ and $\mathrm{Cd}$ based on retention time using kaolinite and bentonite media filters at optimized $\mathrm{pH}$, initial conc. $=100 \mathrm{ppm}$ and media filter height $=42 \mathrm{~cm}$

The flow rate (Q), expressed as the volume of filtered synthetic wastewater passing through the upflow kaolinite and bentonite media filters per unit retention time, was determined using the formula: $\mathrm{Q}=\mathrm{V} / \mathrm{t}(1)$ where $\mathrm{V}$ is volume of liquid (L) passing through the system during retention time, $\mathrm{t}$ (hr).The results showed that the removal efficiency of $\mathrm{Cr}$ and $\mathrm{Cd}$ increased with decreasing flow rate as it function in retention time.

Promising reduction of chromium and cadmium concentrations from aqueous solutions by filtration using upflow kaolinite and bentonite media filters were achieved. Fig (5) clears that the \% removal efficiency of $\mathrm{Cr}$ and $\mathrm{Cd}$ increased with the increase of retention time for both media filters. The optimum $\% \mathrm{Cr}$ and $\mathrm{Cd}$ removal efficiency were $96 \%$ and $91 \%$ for kaolinite and bentonite respectively at $\mathrm{RT}=24$ hours. The difference between the highest \% removal efficiency of $\mathrm{Cr}$ and $\mathrm{Cd}$ at $\mathrm{RT}=72$ hours and the optimum \% removal efficiency achieved of $\mathrm{Cr}$ and $\mathrm{Cd}$ at $\mathrm{RT}=24$ hours not more than (2-4\%)which is not proportional to the increased operating cost associated with the increasing of retention time.Comparable outcomes with regard to the removal of heavy metals, by using different types of filters were reported by various researchers (Farizogluet al., 2003; Krishna et al., 2014 and Mekonnenet al., 2017). 


\subsection{Initial Concentrationsof Cr and Cd Analysis}

Fig. (6) determines the relationship between the \% removal of chromium and cadmium ionswith regard to different initial heavy metals concentrations of raw synthetic wastewater samples using kaolinite and bentonite media filters. The initial concentrations for chromium and cadmium are 100, 200, 300, 400 and $500 \mathrm{ppm}$ at optimum $\mathrm{pH}=6.0$ and 5.0 and optimum retention time $=24 \mathrm{hr}$, respectively which achieved from previous experiments. The different concentrations of $\mathrm{Cr}$ and $\mathrm{Cd}$ ions were explored separately and one by one.

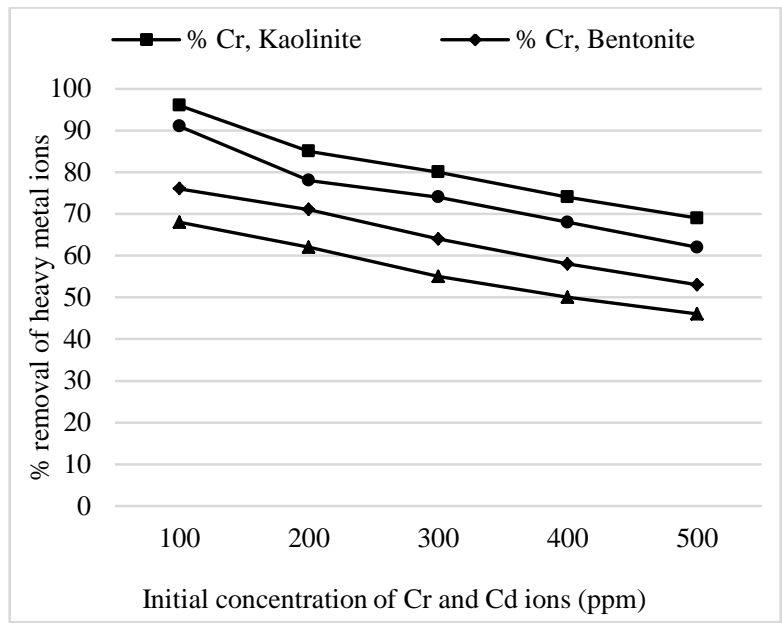

Fig.6The relation between initial concentration of heavy metal ions and \% removal of $\mathrm{Cr}$ and $\mathrm{Cd}$ using

kaolinite and bentonite media filters filters at optimized $\mathrm{pH}, \mathrm{RT}=24 \mathrm{hr}$ and media filter height $=42$ $\mathrm{cm}$

Fig. (6) illustrates that the \% removal efficiency of $\mathrm{Cr}$ and $\mathrm{Cd}$ decreases with the increase of initial concentration of $\mathrm{Cr}$ and $\mathrm{Cd}$ ions for both media filters. The optimum \% $\mathrm{Cr}$ and $\mathrm{Cd}$ removal efficiency were $96 \%$ and $91 \%$ for kaolinite and bentonite respectively at initial concentration of $\mathrm{Cr}$ and $\mathrm{Cd}=100 \mathrm{ppm}$. It also shows that \% removal efficiency of $\mathrm{Cr}$ and $\mathrm{Cd}$ decreased gradually till it reached $69 \%$ and $62 \%$ for kaolinite and bentonite respectively at initial concentration of $\mathrm{Cr}$ and $\mathrm{Cd}=500 \mathrm{ppm}$ at the same boundary conditions. This was due to the increase of heavy metal ions concentration that competed on the operative site; also this may be limited active site of filter media. Therefore, more heavy metal ions were left without removing from solution at higher concentration levels .This finding can be attributed to the increase of selectivity in heavy metals ions by increasing its concentrations in the aqueous solutions. The valences of the replacing cations have a strong effect on heavy metal ions equilibrium and thus on the removal efficiency of $\mathrm{Cr}$ and $\mathrm{Cd}$ ions concentrations. This consequence agreed with (Brigattiet al., 1999) with regard to the removal of different heavy metal ions using different clay types.

\subsection{Height of media filter analysis}

Fig. (7) governs the relationship between the \% removal of chromium and cadmium ions with regard to different media filter heights using kaolinite and bentonite media filters. The media filter heights for kaolinite and bentonite medias are 10.5, 21.0, 31.5 and $42 \mathrm{~cm}$ at optimized $\mathrm{pH}$, retention time $=24 \mathrm{hr}$ and initial concentration for $\mathrm{Cr}$ and $\mathrm{Cd}$ ions $=100 \mathrm{ppm}$ respectively which achieved from previous experiments. The different media filter heights of $\mathrm{Cr}$ and $\mathrm{Cd}$ ions solutions were explored separately and one by one.

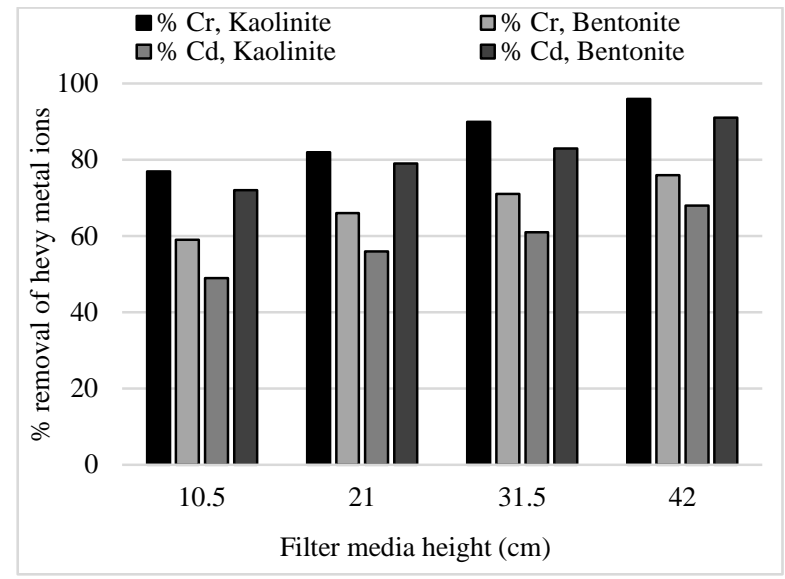

Fig.7The relation between filter media height and \% removal of $\mathrm{Cr}$ and $\mathrm{Cd}$ using kaolinite and bentonite media filter at optimized $\mathrm{pH}, \mathrm{RT}=24 \mathrm{hr}$ and initial concentration $=100 \mathrm{ppm}$

Figure (7) shown that the \% removal efficiency of $\mathrm{Cr}$ and $\mathrm{Cd}$ required to reach the equilibrium state increases as the bed height increases for both media filters. The optimum \% $\mathrm{Cr}$ and $\mathrm{Cd}$ removal efficiency were $96 \%$ and $91 \%$ for kaolinite and bentonite respectively at media filter height $=42 \mathrm{~cm}$. It also shows that minimum \% removal efficiency of $\mathrm{Cr}$ and $\mathrm{Cd}$ achieved reached $77 \%$ and $72 \%$ for kaolinite and bentonite respectively at media filter height $=10.5 \mathrm{~cm}$ at the same boundary conditions. This can be accredited to the presence of more available sites of the removal in the media when increasing the media filter height and, therefore, the required \% removal efficiency of $\mathrm{Cr}$ and $\mathrm{Cd}$ reaching the equilibrium state increases.

Besides, the accumulation of $\mathrm{Cr}$ and $\mathrm{Cd}$ ions in the media filter can be seen that the \% removal efficiency of $\mathrm{Cr}$ and $\mathrm{Cd}$ increases when the media filter height increases, because using extra amount of kaolinite and bentonite clay results in extra medias for filtration, long flow paths and more contact time between the chromium and cadmium ions solutions and media filter clay particles. This phenomenon could be because that the increase in media filter height of the filter column results in an increase in the breaking point as well as the media filter burnout time. This is due to an increase 
for clay amount of media filter, which translates into an increase in the service area and specific surfaces available for filtration. This result agreed with (Tan et al., 2008) and (Auta and Hameed, 2014).

\subsection{Regression models for Cr and Cd removal efficiency}

From the experimental data, by applying linear equation regression models with confidence level 95\% to correlate, predict and understand which among the independent variables $\left(\mathrm{X}_{1}, \mathrm{X}_{2}, \mathrm{X}_{3}\right.$ and $\left.\mathrm{X}_{4}\right)$ are related to the dependent variable $(Y)$, and to explore the forms of these relationships. After several trials to minimize the residual mean square (RMS) and achieve the highest, value of $R^{2}$. Results of the experimental data show that the best empirical correlation achieved the best fitting of predicted \% removal of $\mathrm{Cr}$ using kaolinite clay that gives the highest value of $\left(R^{2}=0.995\right)$ which can be expressed as Eq. (2). On the other hand, results of the experimental data show that the best empirical correlation achieved the best fitting of predicted \% removal of $\mathrm{Cd}$ using bentonite clay that gives the highest value of $\left(\mathrm{R}^{2}=0.988\right)$ which can be expressed as Eq. (3).The results of regression models indicate that the most influential independent variables in the \% removal efficiency of $\mathrm{Cr}$ and $\mathrm{Cd}$ ions from aqueous solutions using kaolinite and bentonite clay upflow filter $\mathrm{pH}$, retention time and height media filter, which affects positively. The least influential independent variable is the initial concentrations of $\mathrm{Cr}$ and $\mathrm{Cd}$ ions, which affects negatively as can be seen in the equations (2) and (3).

$\mathrm{Y}_{\mathrm{Cr}}=11.426 \mathrm{X}_{1}+0.326 \mathrm{X}_{2}-0.043 \mathrm{X}_{3}+0.371 \mathrm{X}_{4}(2)$

$\mathrm{Y}_{\mathrm{Cd}}=10.799 \mathrm{X}_{1}+0.47 \mathrm{X}_{2}-0.035 \mathrm{X}_{3}+0.422 \mathrm{X}_{4}(3)$

For \% Cr removal efficiency regression model, fig. (8) shows a plot of the predicted \% removal of $\mathrm{Cr}$ using kaolinite clay comparing to the experimental data results. The Correlation Coefficient $\mathrm{R}^{2}$ is 0.995 , means all values of \% removal of $\mathrm{Cr}$ using kaolinite clay obtained from the empirical correlation are very close to values determined experimentally.

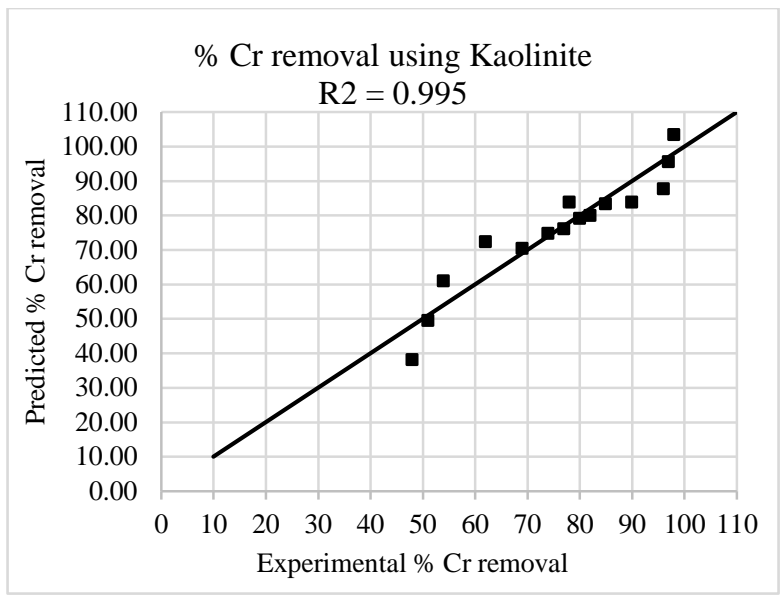

Fig.8 Correlation between experimental and predicted $\%$ Cr removal using kaolinite clay media filter
For \% Cd removal efficiency regression model, fig. (9) shows a plot of the predicted \% removal of $\mathrm{Cd}$ using bentonite clay comparing to the experimental data results. The Correlation Coefficient $\mathrm{R}^{2}$ is 0.988 , means all values of \% removal of $\mathrm{Cd}$ using bentonite clay obtained from the empirical correlation are very close to values determined experimentally.

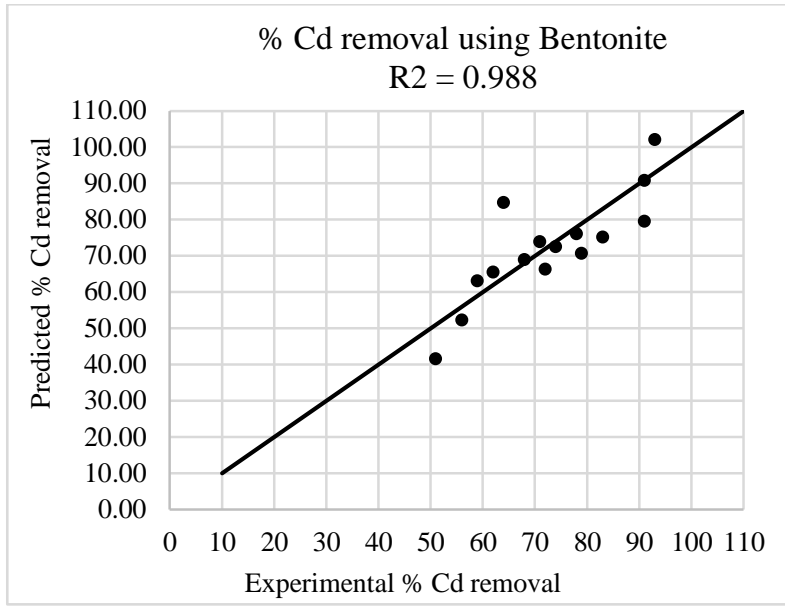

Fig.9 Correlation between experimental and predicted $\%$ Cd removal using Bentonite clay media filter

\section{Conclusion}

The present study showed that natural kaolinite and bentonite clays are a hopeful and encouraging media filters for the removal of chromium and cadmium ions from synthetic aqueous solutions over a wide range of concentrations. The results showed the following:

-Chromium ions concentration were found to remove strongly and efficiently through the kaolinite media filter with $96 \%$ removal efficiency at optimum boundary conditions.

-Cadmium ions concentration were found to remove strongly and efficiently through the bentonite media filter with $91 \%$ removal efficiency at optimum boundary conditions.

-Kaolinite clay is more effective to remove chromium ions from raw synthetic wastewater than bentonite clay.

- Bentonite clay is operative to remove cadmium ions from raw synthetic wastewater than kaolinite clay.

- Optimum conditions for $\mathrm{Cr}$ and $\mathrm{Cd}$ ions removal were $\mathrm{pH}$ of solution 6.0 and 5.0 respectively through kaolinite and bentonite clay filter media separately at retention time $=24 \mathrm{hr}$, initial concentration $100 \mathrm{ppm}$ and media filter height $=42 \mathrm{~cm}$.

- The most essential factor affecting the removal of $\mathrm{Cr}$ and $\mathrm{Cd}$ ions from raw synthetic wastewater was $\mathrm{pH}$ vaule. It was found that the increasing of solution $\mathrm{pH}$ more than 6.0 and 5.0 respectively may cause precipitation rather than filtration.

- The removal efficiency of $\mathrm{Cr}$ and $\mathrm{Cd}$ increases with increasing retention time and media filter height. On other hand, it decreases with increasing initial 
concentration of heavy metal ions in raw synthetic wastewater.

- The Cr and Cd ions removal efficiency were depended on the $\mathrm{pH}$, retention time, initial concentration of heavy metals ions solutions and the media filter height, i.e., the removal efficiency of $\mathrm{Cr}$ and $\mathrm{Cd}$ ions from the aqueous solution increases with the increases of retention time and media filter height.

- The most influential independent variables in the \% removal efficiency of $\mathrm{Cr}$ and $\mathrm{Cd}$ ions from aqueous solutions using kaolinite and bentonite clay upflow filter separately were $\mathrm{pH}$, retention time and height media filter, which affects positively.

- The experimental data show that the best empirical correlation achieved the highest fitting of predicted \% removal of $\mathrm{Cr}$ and $\mathrm{Cd}$ using kaolinite and bentonite clay separately that gives the highest value of $\left(\mathrm{R}^{2}=0.995\right.$ and 0.988 ) respectively.

- The present study concludes that the use of upflow filter media for $\mathrm{Cr}$ and $\mathrm{Cd}$ ions removal from heavy metal aqueous solutions using natural kaolinite and bentonite clay respectively and separately is an economical substitute, cost effective and environmental friendly to conventional water treatments.

\section{Acknowledgement}

The author expresses appreciation to the staff of employees of Environmental Engineering Laboratory Faculty of engineering - Zagazig University.

\section{References}

Kurniawan, A., Ismadji, S., Soetaredjo, F. E., Ayucitra, A., (2014). Natural Clays/Clay Minerals and Modified Forms for Heavy Metals Removal. Chapter 11, on http://pubs.rsc.orgdoi:10.1039/9781782620174-00213.
Amarasinghe, B.M.W.P.K., Williams, R.A., (2007). Tea waste as a low cost adsorbent for the removal of $\mathrm{Cu}$ and $\mathrm{Pb}$ from wastewater.Chemical Engineering Journal, 132, 299-309.

APHA, (2005).Standard Methods for the Examination of Water and Wastewater, 21st ed., American Public Health Association, Washington, DC.

Bassett, J., Denny, R., Jeffery, H., and Mendham, J., (1978). Vogel's Textbook of Quantitative Inorganic Analysis," William Clowes\& Sons Limited, London.

Oladoja, N.A. and Imohimi O. A., (2005). Studies on the Use of Fortified Kaolinitic Soil-Clay in Industrial Wastewater Treatment, Water Qual.Res. J. Canada, 40, No. 4, 500-509.

Farizoglu B., Nuhoglu A., Yildiz E. and Keskinler B., (2003). The performance of pumice as a filter bed material under rapid filtration conditions, Filtration \& Separation, 40(3) 41-47.

Krishna R. Reddy, Tao Xie, Sara Dastgheibi, (2013).Nutrients Removal from Urban Storm water by Different Filter Materials, Water Air Soil Pollut, 225:1778.

Mekonnen B.,Seyoum L. and Mohammed M. K., (2017), Removal of Hazardous Pollutants from Tannery Wastewater by Naval Filter Medium (Pumice) Through Adsorption and Filtration Method. IOSR Journal of Environmental Science, Toxicology and Food Technology (IOSR-JESTFT) Volume 11, Issue 9 Ver. II (September. 2017), PP 38-45

Brigatti, M. F., Franchini, G., Frigieri, P., Gardinali, C., Medici, L., Poppi, L., (1999). Treatment of industrial wastewater using zeolitite and sepiolite, natural microporous materials, Can. J. Chem. Eng., 77, 163-168.

Tan, I. A. W., Ahmad, A. L., Hameed, B. H., (2008) Adsorption of basic dye using activated carbon prepared from oil palm shell: batch and fixed bed studies, Desalination, 225, 1328.

Auta, M., Hameed, B.H., (2014).Chitosan-clay composite as highly effective and low-cost adsorbent for batch and fixed-bed adsorption of methylene blue, Chem. Eng. J, 237 352-361. 